\title{
Role of Recombinant Human Erythropoietin and Parenteral Iron on Autologous Blood Donation in Neurosurgical Patients
}

\author{
Ajayveer Singh $^{1}$, Vinod Kumar Srivastava ${ }^{2}$, Vikash Mandhar ${ }^{3}$, Ashish Kannaujia ${ }^{4}$ \\ ${ }^{1,2,3} \mathrm{MD}$, Senior Resident, Department of Anesthesia, King Georges Medical University, Lucknow \\ ${ }^{4} \mathrm{MD}$, Assistant Professor, Department of Anesthesia, SGPGIMS, Lucknow
}

\begin{abstract}
Patient undergoing neurosurgery of intracranial and major spine surgery often require perioperative allogenic blood transfusion to avoid anaemia and for better patient outcome from surgical stress as well as from anaesthesia. However some complication like transfusion reaction and infection associated with allogenic blood transfusion leads to concept of autologous blood transfusion. We studied effect of autologous blood transfusion in major elective neurosurgery .
\end{abstract}

Keywords: Autologous blood, Allogenic blood, Recombinant human erythropoietin (rHuEPO), Parenteral iron, Folic acid

\section{Introduction}

Any type of elective or emergency surgery is usually associated with blood loss and conventionally it is given as allogenic blood transfusion. Blood transfusions are directly lethal in only minority of cases. However despite the advent of modern transfusion medicine this type of transfusion has its own demerits like transfusion reaction, transmission of infection and immunological reactions. Infections which can be transmitted by blood transfusions include bacterial, parasitic infections such as plasmodium (malaria), Trypanosoma cruzi (Chaga's disease) and Treponema pallidum (Syphilis) and some viral like Hepatitis B and C virus, human immunodeficiency virus (type 1 and type 2),cytomegalovirus, Epstein - Barr virus and human $\mathrm{T}$ cell leukemia virus. Another problem related with allogenic blood is availability of same blood group.

All above complication can be minimized by reducing the exposure to allogenic blood. The most logical solution will be the reduction of perioperative blood loss which can be done by meticulous surgery, hemostasis and several anaesthesiological techniques. These techniques include controlled hypotension, positioning methods, regional anesthesia, use of drugs like aprotinin, dipyridamole and desmopressin. However for a large group of patients transfusions are still required and therefore it is worthwhile looking for the best alternative to allogenic blood.

Being aware of above all complication and necessity of blood transfusion in some circumstances introduced a concept of autologous blood transfusion in elective surgery.

Preoperative autologous donation (PAD) is the most popular and widely used of the autologous options. In this principle patients planning elective surgery requiring blood transfusion may be able to donate blood for themselves prior to surgery. Patient's health status and red blood count (hemoglobin or hematocrit) determine whether they can donate. PAD collections should be considered for patients likely to undergo surgery with anticipated intraoperative blood loss like major orthopedic procedures, most commonly total joint replacement, vascular surgery, cardiac surgery, thoracic surgery and neurosurgery.

Patient was supplemented with iron and erythropoietin to build-up patient hemoglobin status almost same at the time of admission. The most obvious benefit of PAD for the donor/patient is safest freedom from concern about infectivity of the blood. (Vanderlinde ES et al 2002)

Recombinant Human Erythropoietin, (rHuEPO) injection, a monomeric glycoprotein hormone consisting of a 165 amino acid polypeptide chain manufactured by recombinant DNA technology, has the same biological effects as endogenous erythropoietin and is produced by Chinese Hamster Ovary (CHO) mammalian cell lines with stably integrated human erythropoietin gene. The product contains the identical amino acid sequence of isolated natural erythropoietin. The protein has a molecular weight of $18 \mathrm{kDa}$. When it administered in autologous blood donor effective erythropoiesis results. Tasaki et al (1992), Kulier et al (1993) and Kajikawa et al (1994)

Oral iron takes longer time to replenish the iron stores of the body and large doses of oral iron are usually not tolerated well because of its side effects such as stomach upset, pain and cramps, constipation, dark colored stool, presence of blood in stools, nausea, rash, hives and swelling, bluish colored nails and lips, tingling sensation in hands or feet, double vision and weakness, teeth discoloration.

Parental iron was used in this study after PAD because parenteral iron replenishes body iron stores fast. Schindler et al (1994)

\section{Material and Methods}

This study was randomized, prospective double blind study carried out on admitted patient of Gandhi memorial and associated hospital after getting approval from Ethical 


\section{International Journal of Science and Research (IJSR) \\ ISSN (Online): 2319-7064 \\ Index Copernicus Value (2013): 6.14 | Impact Factor (2015): 6.391}

Committee, King George's Medical University, Uttar Pradesh, Lucknow in neurosurgery department.

For this purpose total of 30 patients for elective intracranial and major spine surgery of either sex of age group between 18-60 yrs and ASA grade I \&II were submitted that have anticipated intraoperative blood loss and blood transfusion required. Patients of renal, pulmonary, cardiovascular, neuromuscular and deranged liver function test were excluded. The cases were enrolled into three groups, the first one called control group (group A) in which patient were managed conventionally by allogenic blood transfusion and another groups $\mathrm{B}$ and $\mathrm{C}$ called study group includes those patients who managed by autologous blood transfusion. Group B received parenteral iron and folic acid where as group $\mathrm{C}$ received recombinant erythropoietin besides parenteral iron and folic acid. Patients were admitted 14 days before surgery and well counselled and explained about the procedure. At the time of admission blood sample was taken and send for hemoglobin, hematocrit and other routine investigation. One unit of blood from patient was withdrawn 14 days before surgery and stored in transfusion medicine department. Parenteral iron dose of $100 \mathrm{mg} /$ day for patient weighing $<50 \mathrm{~kg}$ and $200 \mathrm{mg} /$ day for patients weighing $>50 \mathrm{~kg}$, folic acid in dose of $500 \mu \mathrm{g}$ per day and rHuEPO in dose of $300 \mathrm{IU} / \mathrm{kg}$ once weekly.

After arrival in operating room intravenous access was secured and ECG, pulse oximetry, noninvasive blood pressure, temperature and urine output was monitored at regular interval till shifting of the patient to post operative room. A venous blood sample was taken for preoperative estimation of hemoglobin and hematocrit. All cases of intracranial and spinal surgery was done under general anaesthesia.

Blood loss was quantitated intra-operatively by measuring the suction-volume, and then subtracting the volume of irrigation fluid, by weighing soaked sponges/ gauge pieces and subtracting from their dry preoperative weight. Postoperative blood loss was quantitated and added to the intraoperative blood loss, to calculate the total blood loss throughout the study period. The duration of surgery and anaesthesia was also recorded. Any local or systemic complications of the drug under study was also observed. The observations were subjected to statistical analysis.

\section{Results}

Thirty patients that required neurosurgical interventions have been evaluated in this study age range was $18-60$ years, 22 were males and 8 were females. All the patients underwent intervention in the form of either cranial or spine surgeries. Patients allocated in three groups, of which Group A patients were considered as control group. Group B patients underwent preoperative autologous blood donation and received parenteral iron and folic acid. Group $C$ patients also underwent preoperative autologous blood donation, and received parenteral iron, folic acid and recombinant human erythropoietin.

Statistical analysis was done on SPSS statistical analysis software. The value were represented in mean \pm SD and numbers (\%). Analysis of variance (ANOVA) was used to test the mean in groups. The paired ' $t$ ' test was used to test the significance of change in groups from baseline. Unpaired ' $t$ ' test was used to test the significance of change in two groups. Chi square test was used for categorical data. 'p' $\leq$ 0.05 were taken as statistically significant.

Distribution of patient according to age, gender, ASA grade, BMI was statistically not significant. Table 1 , shows means age of patients in group A,B and C was $42.20 \pm 13.64,34.40$ \pm 14.33 and $38.20 \pm 14.57$ respectively. On comparing the data statistically, no significant intergroup difference was $\operatorname{observed}(\mathrm{p}=0.48)$

Table 2 shows distribution of subjects according to their gender and on comparing data statistically no significant intergroup difference was observed $(\mathrm{p}=0.50)$

Table 3 shows comparison of subjects according to their BMI and on comparing data statistically no significant intergroup difference was observed $(\mathrm{p}=0.12)$

Table 4 shows comparison of Hemoglobin $(\mathrm{gm} / \mathrm{dl})$ in different group at different time interval that means at baseline, preoperative and postoperative day. On comparing data in group B and C statistically significant difference of baseline and preoperative hemoglobin $(\mathrm{p}=0.04$ and $<0.001)$ was found but more in group $\mathrm{C}$ than $\mathrm{B}(\mathrm{t}=8.6$ in $\mathrm{B}$ than 2.37 in group $\mathrm{C}$ ).In group $\mathrm{A}$ no statistically significant difference in hemoglobin at admission and preoperative was observed.

Table 5 shows comparison of hematocrit in different group at different time interval that means at baseline, preoperative and postoperative day. On comparing data in group B and C statistically significant difference of baseline and preoperative hemoglobin ( $\mathrm{p}=0.04$ and $<0.001$ ) was found but more in group $\mathrm{C}$ than $\mathrm{B}(\mathrm{t}=9.25$ in $\mathrm{B}$ than 2.33 in group $\mathrm{C})$.In group A no statistically significant difference in hematocrit at admission and preoperative was observed.

\section{Discussion}

Our study "Role of parenteral iron and recombinant human erythropoietin with parenteral iron on autologous blood donation in neurosurgical patients" was conducted in The Department of Anaesthesiology, King George's Medical University, Lucknow.

Newer ideas like autologous blood donation and role of iron and recombinant human erythropoietin in autologous donation have emerged in the last few decades.

Erythropoiesis involves the close interaction of iron and erythropoietin. In essence, erythropoietin is the accelerator that drives erythropoiesis. Iron is the fuel for the production of new red blood cells. When the two are coupled, red cell production moves briskly and efficiently. Dudrick SJ, et al (2002)

In previous study it is concluded that preoperative autologous blood donation decreases need for allogenic blood transfusion. Price et al (1996), Bezwada et al (2003), Goldman et al (2002) 


\section{International Journal of Science and Research (IJSR) \\ ISSN (Online): 2319-7064}

Index Copernicus Value (2013): 6.14 | Impact Factor (2015): 6.391

Our study also showed that in group $\mathrm{C}$ which were given parenteral iron with folic acid along with erythropoietin shows statistically significant increase in preoperative and baseline hemoglobin and hematocrit than group B which were not given erythropoietin. There is also less need of allogenic blood transfusion in group c than other group.

\section{Conclusion}

From our study it was shown that significant increase in $\mathrm{Hb}$ and hematocrit at preoperative time from baseline value in group $\mathrm{B}$ and $\mathrm{C}$ but more in $\mathrm{C}$. It is concluded from our study that when erythropoietin is given in preoperative blood donor with iron and folic acid supplement effective erythropoiesis results. When autologous blood is used for blood loss there is less chances of using allogenic blood transfusion. Role of parenteral iron with folic acid to maintain hemoglobin and hematocrit is more significant when co-administered with erythopoietin so rHuEPO should always be used in preoperative autologous blood donor for better outcome of patients.

\section{References}

[1] Bezwada HP, Nazarian DG, Henry DH, Booth RE. Preoperative use of recombinant human erythropoietin before total joint arthroplasty. J Bone Joint Surg Am. 2003; 85-A(9) : 1795-800.

[2] Price TH, Goodnough LT, Vogler WR, Sacher RA, Hellman RM, Johnston MFM, Bolgiano DC, Abels RL. The effect of recombinant human erythropoietin on the efficacy of autologous blood donation in patients with low hematocrits. Transfusion 1996; 36(1) : 29 - 36.

[3] Goldman M, Savard R, Long A, Gélinas S, Germain M. Declining value of preoperative autologous donation. Transfusion 2002; 42(7) : 819 .

[4] Schindler E, Scholz S, Boldt J, Zickmann B, Knothe C, Dietrich G, Hempelmann G. Effectiveness of oral versus parenteral iron substitution in autologous blood donors. Infusionsther Transfusionsmed. 1994; 21(4) : 236-41.
[5] Tasaki T, Ohto H, Hashimoto C, Abe R, Saitoh A, Kikuchi S. Recombinant human erythropoietin for autologous blood donation: effects on perioperative redblood-cell and serum erythropoietin production. The Lancet 1992; 339 : 773 - 775.

[6] Kulier AH, Gombotz H, Fuchs G, Vuckovic U, Metzler H. Subcutaneous Recombinant Human Erythropoietin and Autologous Blood Donation Before Coronary Artery Bypass Surgery. A \& A 1993; 76(1): 102-106.

[7] Kajikawa M, Nonami T, Kurokawa T, Hashimoto S, Harada A, Nakao A, Takagi H. Autologous blood transfusion for hepatectomy in patients with cirrhosis and hepatocellular carcinoma: use of recombinant human erythropoietin. Surgery 1994;115(6):727-734

[8] Vanderlinde ES, Heal JM, Blumberg N. Autologous transfusion. BMJ 2002; 324:772.

[9] Dudrick SJ, O'Donnell JJ, Raleigh DP, Matheny RG, Unkel SP. 1985. Rapid restoration of red blood cell mass in severely anemic surgical patients who refuse transfusion. Arch Surg 120:721-727.

Tables:

Table 1: Age distribution of different groups

\begin{tabular}{|c|c|c|}
\hline & Number & mean $+S D($ in years $)$ \\
\hline Group A & 10 & $42.20 \pm 13.64$ \\
\hline Group B & 10 & $34.40 \pm 14.33$ \\
\hline Group C & 10 & $38.20 \pm 14.57$ \\
\hline
\end{tabular}

$\mathrm{F}=0.76, \mathrm{p}=0.48(\mathrm{NS}$

Table 2: Sex distribution

\begin{tabular}{|c|c|c|c|c|c|c|}
\hline \multirow{3}{*}{ Gender } & \multirow{2}{*}{\multicolumn{2}{|c|}{ Group A }} & \multirow{2}{*}{\multicolumn{2}{|c|}{ Group B }} & \multirow{2}{*}{\multicolumn{2}{|c|}{ Group $C$}} \\
\hline & & & & & & \\
\hline & No. & $\%$ & No. & $\%$ & No. & $\%$ \\
\hline Male & 6 & 60 & 8 & 80 & 8 & 89 \\
\hline Female & 4 & 40 & 2 & 20 & 2 & 20 \\
\hline Total & 10 & 100 & 10 & 100 & 10 & 100 \\
\hline
\end{tabular}

Table 3: Body mass index of different groups (BMI)

\begin{tabular}{|l|c|c|}
\hline & Number & mean $\pm \mathrm{SD}\left(\mathrm{kg} / \mathrm{mt}^{2}\right)$ \\
\hline Group A & 10 & $22.87 \pm 1.95$ \\
\hline Group B & 10 & $22.52 \pm 1.49$ \\
\hline Group C & 10 & $24.25 \pm 2.27$ \\
\hline
\end{tabular}

$\mathrm{F}=2.25, \mathrm{p}=0.12(\mathrm{NS})$

Comparison of baseline, preoperative and postoperative haemoglobin and hematocrit of all patient in different groups are shown in table $4 \& 5$.

Table 4: Comparison of Haemoglobin $(\mathrm{gm} / \mathrm{dl})$ in different group at different time interval $(\mathrm{n}=10)$

\begin{tabular}{|c|l|c|c|c|}
\hline \multicolumn{2}{|c|}{} & Baseline & Preoperative & Postoperative (Day 3) \\
\hline \multirow{4}{*}{ Group A } & Mean \pm S.D. & $11.61 \pm 1.09$ & $11.56 \pm 1.10$ & $10.54 \pm 0.63$ \\
\cline { 2 - 5 } & Change from baseline & - & $0.05 \pm 0.23$ & $1.07 \pm 0.86$ \\
\cline { 2 - 5 } & 't' value & - & 0.70 & 3.95 \\
\cline { 2 - 5 } & 'p' value & - & $0.5(\mathrm{NS})$ & 0.003 (Sig.) \\
\hline \multirow{4}{*}{ Group B } & Mean+S.D. & $11.88 \pm 0.93$ & $12.2 \pm 1.04$ & $11.74 \pm 0.93$ \\
\cline { 2 - 5 } & Change from baseline & - & $0.32 \pm 0.43$ & $0.14 \pm 0.43$ \\
\cline { 2 - 5 } & 't' value & - & 2.37 & 1.04 \\
\cline { 2 - 5 } & 'p' value & - & $0.04(\mathrm{Sig})$. & $0.33(\mathrm{NS})$ \\
\hline \multirow{4}{*}{ Group C } & Mean $\underline{\text { S.D. }}$ & $11.37 \pm 0.85$ & $12.30 \pm 0.74$ & $11.37 \pm 0.72$ \\
\cline { 2 - 5 } & Change from baseline & - & $0.93 \pm 0.34$ & $0.03 \pm 0.42$ \\
\cline { 2 - 5 } & 't' value & - & 8.6 & 0.23 \\
\cline { 2 - 5 } & 'p' value & - & $<0.001$ (Sig.) & 0.83 (NS) \\
\hline
\end{tabular}




\section{International Journal of Science and Research (IJSR)}

ISSN (Online): 2319-7064

Index Copernicus Value (2013): 6.14 | Impact Factor (2015): 6.391

Table 5: Comparison of Hematocrit (\%) in different groups at different time interval $(\mathrm{n}=10)$

\begin{tabular}{|c|c|c|c|c|}
\hline & & Baseline & Preoperative & Postoperative (Day 3) \\
\hline \multirow{4}{*}{ Group A } & Mean+S.D. & $34.70 \pm 3.36$ & $34.60 \pm 3.35$ & $31.40 \pm 1.96$ \\
\hline & Change from baseline & - & $0.01 \pm 0.56$ & $3.3 \pm 2.49$ \\
\hline & 't' value & - & $0 . \overline{56}$ & 4.18 \\
\hline & 'p' value & - & $0.5(\mathrm{NS})$ & 0.002 (Sig.) \\
\hline \multirow{4}{*}{ Group B } & Mean+S.D. & $35.3 \pm 2.75$ & $36.2+2.93$ & $35 \pm 2.67$ \\
\hline & Change from baseline & - & $0.9 \pm 1.37$ & $0.3 \pm 1.49$ \\
\hline & 't' value & - & 2.33 & 0.63 \\
\hline & 'p' value & - & 0.04 (Sig.) & $0.54(\mathrm{NS})$ \\
\hline \multirow{4}{*}{ Group C } & Mean+S.D. & $33.80 \pm 2.257$ & $36.4 \pm 2.36$ & $33.3 \pm 2.35$ \\
\hline & Change from baseline & - & $0.6 \pm 1.17$ & $0.6 \pm 0.24$ \\
\hline & 't' value & - & 9.25 & 1.34 \\
\hline & 'p' value & - & $<0.001$ (Sig.) & $0.21(\mathrm{NS})$ \\
\hline
\end{tabular}

